\title{
Pronostic Factors of Cerebral Toxoplasmosis in Department of Infectious and Tropical Diseases at Donka National Hospital
}

\author{
Mamadou Saliou Sow ${ }^{1}$, Karamba Sylla1, Diao Cissé2, Fodé Abass Cissé ${ }^{3}$, Ibrahima Bah1, \\ Kadiatou Cissé1, Kadio Jean Jaques Olivier Kadio²
}

\author{
${ }^{1}$ Department of Infectious and Tropical Diseases at Donka National Hospital, Conakry, Guinea \\ ${ }^{2}$ Chair of Public Health, Conakry, Guinea \\ ${ }^{3}$ Neurology Department of Ignace Deen National Hospital, Conakry, Guinea \\ Email: *smsaliou@gmail.com
}

How to cite this paper: Sow, M.S., Sylla, K., Cissé, D., Cissé, F.A., Bah, I., Cissé, K. and Kadio, K.J.J.O. (2019) Pronostic Factors of Cerebral Toxoplasmosis in Department of Infectious and Tropical Diseases at Donka National Hospital. Advances in Infectious Diseases, 9, 243-251.

https://doi.org/10.4236/aid.2019.93018

Received: May 16, 2019

Accepted: September 9, 2019

Published: September 12, 2019

Copyright $\odot 2019$ by author(s) and Scientific Research Publishing Inc. This work is licensed under the Creative Commons Attribution International License (CC BY 4.0).

http://creativecommons.org/licenses/by/4.0/

\begin{abstract}
Objectives: To identify predictive factors for poor prognosis during cerebral toxoplasmosis at Donka Hospital. Methods: It was a retrospective study of descriptive and analytic type lasting one year six months (18 months) from January $1^{\text {st }}, 2016$ to June $30^{\text {th }}, 2017$ which involved patients admitted and hospitalized for cerebral toxoplasmosis in HIV field. Data enter was performed by Epi data 3.1 software and SPSS 21 software for statistical analysis. The threshold of significance was $\mathrm{p}<0.05$. Results: We observed 87 cases of cerebral toxoplasmosis $(\mathrm{CT})$. The mean age was $38.53 \pm 12.16$. The clinical signs were mainly infectious syndrome (100\%), headache (69.0\%), confusion (46.0\%) and meningeal syndrome (41.4\%). The lethality was $37.9 \%$. Living with a partner $(p=0.007), C D 4$ at initiation of antiretroviral therapy $<200$ cells $/ \mathrm{mm}^{3}(\mathrm{p}=0.009)$, and coma $(\mathrm{p}=0.02)$ were the factors associated with death. Conclusion: This study showed that cerebral toxoplasmosis is associated with very high morbidity and mortality in the Infectious Diseases Department of Donka National Hospital. Living in a relationship, CD4 counts at baseline $<200$ cells $/ \mathrm{mm}^{3}$ and coma were independently associated with death. Special attention to these factors associated with infectious resuscitation and primary prevention in patients with a CD4 T lymphocyte count below 200 cells/mm may improve the prognosis of this pathology.
\end{abstract}

\section{Keywords}

Cerebral Toxoplasmosis, HIV/AIDS, Donka 


\section{Background}

Toxoplasmosis has emerged as a major opportunistic disease in patients with Acquired Immune Deficiency Syndrome (AIDS). It can manifest itself as a potentially fatal encephalitis, due to the reactivation of latent infections in immune suppression associated with the human immunodeficiency virus (HIV) [1] [2]. Toxoplasmosis is at the top of the list of diseases that occur death in patients with AIDS [3]. Although the incidence of cerebral toxoplasmosis (CT) has decreased as a result of antiretroviral therapy (ART), it is still a serious diagnostic and therapeutic problem and a life-threatening condition [4]. Death proportion among toxoplasmosis in AIDS patients is estimated at around 10\% in the United States and up to $30 \%$ in Europe [3]. Associated factors and likelihood survival characteristics of toxoplasmic encephalitis in the era of antiretroviral therapy have not been addressed in our context. Knowledge of these factors could help improve the survival of PLHIV. The objective of our study was to identify predictive factors for poor prognosis during cerebral toxoplasmosis in the field of HIV infection.

\section{Material and Methods}

\subsection{Study Setting and Design}

The Infectious Diseases Department at Donka National Hospital served as our study. It is one of the referral services in the treatment of HIV in the Republic of Guinea.

This was a retrospective study of descriptive and analytical type lasting one year six months from January 1, 2016 to June 30, 2017.

\subsection{Study Population}

The study looked at the records of patients admitted and hospitalized for cerebral toxoplasmosis in HIV field at SMIT at Donka National Hospital.

\subsection{Inclusion Criteria}

We included patients with cerebral toxoplasmosis on HIV field received and hospitalized at the SMIT of Donka National Hospital during the study period.

\subsection{Definition Criteria}

The diagnosis of cerebral toxoplasmosis was retained in an HIV-infected patient with a CD4 count of less than 200 cells/ml, combining intense headaches resistant to usual analgesics, unexplained fever, and focal neurological deficit (hemiplegia or hemiparesis), a syndrome of intracranial hypertension, a disorder of consciousness (agitation, obnubilation, temporal-spatial disorientation, coma).

Cerebral CT revealing one or more images of hypodensity circled by a contrast enhancement (cockade), or hyperdensity.

In cases where imaging was not available, good evolution with Cotrimoxazole allowed the diagnosis of CT to be retained. 


\subsection{Data and Measures}

Socio-demographic characteristics information (age, sex, marital status, residence), antecedents (CD4 and hemoglobin levels at treatment initiation, primary cotrimoxazole prophylaxis), clinical signs (general signs, neurological signs), paraclinical data (toxoplasmic serology and magnetic resonance imaging), treatment and outcome (healed, deceased, referred) were collected in all patients.

\subsection{Data Analysis}

Data enter was performed by Epi data 3.1 software and SPSS 21 software for statistical analysis.

Proportions were calculated for the qualitative variables. Quantitative variables were presented as mean \pm standard deviation. Comparison of proportion was performed by chi2 test or exact fisher. The Student's test was used for the comparison of averages. Univariate analysis and multivariate logistic regression were used to search for factors associated with death. Only variables whose value of p-value was less than or equal to 0.20 in univariate were taken into account in the multivariate analysis. The threshold of significance was set at $\mathrm{p}<0.05$.

\subsection{Ethical Consideration}

Ethical clearance was obtained from the University of Conakry. Participants were informed that the information collected for this research project were kept confidential and information about collected by this study will be stored in a file, without their name, but code number assigned to it.

\section{Results}

\section{Socio-economic demographic and clinical characteristics}

During our study period, 495 patients were hospitalized at the Department of Infectious and Tropical Diseases at national hospital of Donka are not 87 years old for cerebral toxoplasmosis in the field of HIV or $17.58 \%$.

The characteristics of all patients are described in Table 1.

Cerebral toxoplasmosis was indicative of HIV infection in $43.7 \%$ of patients. The clinical picture was dominated by headache (69.0\%); focal neurological signs including seizures (28.7\%) followed by hemiplegia (21.8\%) and hemiparesis $(20.7 \%)$. All patients presented Infectious syndrome.

In the assessment of the state of consciousness $46.0 \%$ was in a state of confusion and $21.8 \%$ in a coma. More than half (78.2\%) of those present have opportunistic infections, including gastrointestinal candidiasis (20.7\%), pulmonary tuberculosis $(10.3 \%)$, genital herpes $(6 \%), 9 \%)$, Kaposi's disease with a proportion of $2.3 \%$. Forty-five patients were cerebral computed tomography $45 / 87 \%$ (Table 2). Among 87 cases of cerebral toxoplasmosis, we observed 33 deaths, a hospital mortality of $37.9 \%$ (Table 3 ).

Factors Associated with the Death of Patients with Cerebral Toxoplasmosis

Univariate analysis shows that patients living with a partner, on patients with 
Table 1. Sociodemographic characteristics of patients with cerebral toxoplasmosis and positive HIV screening for infectious and tropical diseases in Donka National Hospital.

\begin{tabular}{ccc}
\hline Categories & Frequency & Percent (\%) \\
\hline Sex & 45 & 51.7 \\
Male & 42 & 48.3 \\
Female & 38.53 years \pm 12.16 & \\
Mean age \pm standard deviation & & \\
Residence & 65 & 74.7 \\
Urban & 22 & 25.3 \\
Rural environment & & \\
Marital status & 57 & 65.5 \\
Married & 22 & 25.3 \\
Single & 8 & 9.2 \\
Divorced/Widowed & &
\end{tabular}

Table 2. Distribution according to the antecedents, the clinical and paraclinical characteristics of patients with cerebral toxoplasmosis on the ground of HIV infection at the service of infectious and tropical diseases of Donka National Hospital.

\begin{tabular}{lll}
\hline Clinical and Paraclinical Characteristics & Frequency & Percent (\%) \\
\hline
\end{tabular}

Toxoplasmosis indicative of HIV infection $(\mathrm{N}=87)$

$\begin{array}{lll}\text { Yes } & 38 & 43.7 \\ \text { No } & 49 & 56.3\end{array}$

CD4 count at initiation of ART $(\mathrm{N}=87)$

$\begin{array}{lll}<200 & 66 & 75.9 \\ \geq 200 & 21 & 24.1\end{array}$

Primary prophylaxis with cotrimoxazole $(\mathrm{N}=87)$

$\begin{array}{ccc}\text { Yes } & 17 & 19.5 \\ \text { No } & 70 & 80.5 \\ \text { hemiparesis } & 18 & 20.7 \\ \text { Hemiplegia } & 19 & 21.8 \\ \text { Seizures } & 25 & 28.7 \\ \text { headaches } & 60 & 69,0 \\ \text { vomiting } & 19 & 21.8 \\ \text { Visual disorders } & 18 & 20.7 \\ \text { tious syndrome }(\mathbf{N}=\mathbf{8 7}) & 87 & 100 \\ \text { stiffness of the neck }(\mathbf{N}=\mathbf{8 7}) & 36 & 41.4 \\ \text { Confusion } & 40 & 46.0 \\ \text { Coma } & 19 & 21.8\end{array}$




\section{Continued}

Opportunistic infections

Digestive candidiasis

Genital herpes

Kaposi Disease

Toxoplasmic serology $(\mathrm{N}=20)$

IgG

Cerebral computed tomography $(\mathrm{N}=87)$
Pulmonary tuberculosis

18

9

2

45

Table 3. Distribution according to the therapeutic and pronostic characteristics of patients with cerebral toxoplasmosis in the field of HIV infection at the service of infectious and tropical diseases of Donka National Hospital.

\begin{tabular}{ccc}
\hline Caractéristiques & Effectif & Pourcentage \\
\hline $\begin{array}{c}\text { Hospital etiological treatment }(\mathbf{N}=\mathbf{8 7}) \\
\text { Cotrimoxazole }\end{array}$ & 84 & 96.6 \\
$\begin{array}{c}\text { Pyrimethamine and Sulfadiazine } \\
\text { Prognosis }(\mathbf{N}=\mathbf{8 7})\end{array}$ & 3 & 3.4 \\
death & 33 & 37.9 \\
Healed/Enhanced & 46 & 52.87 \\
Average length of hospital stay \\
Average length of hospital stay
\end{tabular}

Table 4. Factors Associated with the Death of Patients with Cerebral Toxoplasmosis in the Field of HIV Infection at the Service of Infectious Diseases at Donka National Hospital.

\begin{tabular}{|c|c|c|c|c|}
\hline & \multicolumn{2}{|c|}{ Univariate } & \multicolumn{2}{|l|}{ Multivariate } \\
\hline & OR (95\% IC) & P-value & Adjusted OR (95\% CI) & P-value \\
\hline Age (continued) & $1.01[0.98-1.05]$ & 0.39 & & \\
\hline \multicolumn{5}{|l|}{ Sex } \\
\hline Male & $1.78[0.74-4.30]$ & 0.19 & $1.64[0.46-5.86]$ & 0.44 \\
\hline Female & Reference & & Reference & \\
\hline \multicolumn{5}{|l|}{ Marital status } \\
\hline in a relationship with & $6.73[2.08-21.77]$ & 0.001 & $9.93[1.89-52.03]$ & 0.007 \\
\hline No In a relationship & Reference & & Reference & \\
\hline \multicolumn{5}{|l|}{ Residence } \\
\hline Urban & $0.70[0.25-1.95]$ & 0.49 & & \\
\hline Rural environment & Reference & & & \\
\hline Toxoplasmosis indic & of HIV infection & & & \\
\hline
\end{tabular}




\section{Continued}

\begin{tabular}{ccccc}
\hline Yes & $0.61[0.25-1.49]$ & 0.28 & & \\
No & Reference & & & \\
CD4 count at initiation of ART $(\mathbf{N}=\mathbf{8 7})$ & & & \\
$<200$ & $18.82[2.38-148.51]$ & 0.005 & $19.04[2.11-171.32]$ & 0.009 \\
$\geq 200$ & Reference & & Reference &
\end{tabular}

Primary prophylaxis with cotrimoxazole

$\begin{array}{ccccc}\text { Yes } & 0.43[0.12-1.47] & 0.18 & 1.02[0.20-5.21] & 0.97 \\ \text { No } & \text { Reference } & \text { Reference } & \end{array}$

\section{Hemiplegia}

$\begin{array}{ccc}\text { Yes } & 0.51[0.16-1.57] & 0.24 \\ \text { No } & \text { Reference }\end{array}$

\section{Hemiparesis}

\begin{tabular}{|c|c|}
\hline Yes & $0.77[0.26-2.32]$ \\
\hline No & Reference \\
\hline
\end{tabular}

\section{Crises convulsives}

$\begin{array}{ccc}\text { Yes } & 0.53[0.19-1.47] & 0.22 \\ \text { No } & \text { Reference }\end{array}$

\section{Headaches}

$\begin{array}{lcl}\text { Yes } & 1.05[0.41-2.70] & 0.90 \\ \text { No } & \text { Reference }\end{array}$

\section{Vomiting}

$\begin{array}{lcl}\text { Yes } & 1.25[0.44-3.52] & 0.67 \\ \text { No } & \text { Reference }\end{array}$

Visual disorders

$\begin{array}{ccccc}\text { Yes } & 0.39[0.11-1.32] & 0.13 & 0.66[0.13-3.29] & 0.61 \\ \text { No } & \text { Reference } & \text { Reference } & \end{array}$

Discreet Stiff neck

$\begin{array}{lcl}\text { Yes } & 1.31[0.54-3.14] & 0.54 \\ \text { No } & \text { Reference }\end{array}$

\section{Confusion}

$\begin{array}{ccccc}\text { Oui } & 1.74[0.72-4.18] & 0.21 & & \\ \text { Non } & \text { Reference } & & & \\ \text { Coma } & & & & \\ \text { Yes } & 3.83[1.32-11.12] & 0.01 & 5.18[1.25-21.42] & 0.02 \\ \text { No } & \text { Reference } & & \text { Reference } & \end{array}$

Anemia (hemoglobin)
$<8$
$1.03[0.40-2.65]$
0.94
$\geq 8$
Référence 
a CD4 count on the initiation of antiretroviral treatment $<200$ cells $/ \mathrm{mm}^{3}$ and on the history of risk during hospitalization. Multivariate analysis, of couple living, CD4 counts at inclusion $<200$ cells $/ \mathrm{mm}^{3}$ and coma were independently associated with death. The risk of death was nearly 10 times higher for living than for those living alone $(\mathrm{OR}=9.93$ [1.89 - 52.03], $\mathrm{p}=0.007)$. Patients with a CD4 count at initiation of antiretroviral therapy $<200$ cells $/ \mathrm{mm}^{3}$ were 19 times more at risk than those with a rate $\geq 200$ cells $/ \mathrm{mm}^{3}(\mathrm{OR}=19.04[2.11-171.32] \mathrm{p}=$ 0.009). Comatose were 5 times more likely to die than non-comatose ( $O R=5.18$ [1.25 - 21.42], $\mathrm{p}=0.02)$.

The proportion of deaths is significantly different between patients with a CD4 count $<200$ and those with a CD4 count $\geq 200(p=0.009)$ (Table 4$)$ at the time of HIV testing.

\section{Discussion}

Aim of this study was to identify the predictive factors for poor prognosis during cerebral toxoplasmosis in the service of infectious diseases at the Donka National Hospital. During six months, we found 87 cases of cerebral toxoplasmosis out of a total of 495 cases, with $17.58 \%$ of hospital frequency.

It is reported in the literature that relates to the state of the nervous system. It is $10 \%$ to $20 \%$ of cases, and more than $50 \%$ of AIDS patients [5]. Other authors found in Côte d'Ivoire in 2007 16\% of cases of cerebral toxoplasmosis [6].

This result denoted delayed diagnosis of HIV in the part and adherence to primary prophylaxis with cotrimozaxole of another party.

Thirty-three cases (33) of deaths were observed with $37.9 \%$ as hospital lethality. Studies in Morocco and Cameroon have revealed respective proportions of lethality of $28.57 \%$ and $29.9 \%$ [7] [8]. These proportions though we will be maintained until our highly active antiretroviral therapy.

This high proportion of mortality was explained after a late diagnosis of the infection, once detected in patients to believe in the disease; this situation associated with the side effects of ARVs causes some patients to consult traditional healers.

Several previous studies of HIV patients on antiretroviral therapy use traditional medicine [9]-[14]. This stay with the healers results in the degradation of the immunity, the appearance of resistance to the treatments leading these patients to the AIDS stage. Finally, it is difficult for parents to honor the prescriptions seen by patients in transit, often with traditional healers or in the labor market. Sanitary facilities not adapted to the management of the base of the financial exhaustion before their admissions to the service of reference.

Multivariate analysis, of couple living, CD4 counts at initiation $<200$ cells $/ \mathrm{mm}^{3}$ and coma were dependently associated with death.

The authors of a study conducted in Senegal in 2013 found that anemia ( $p=$ $0.003)$, high CD8 $+\mathrm{T}$ cell count $(\mathrm{p}=0.009)$ and coma $(\mathrm{p}=0.02)$ were associated factors at death of PHAs with toxoplasmos [15]. 
The risk of death was 19 times higher in people with a CD4 count $<200$ cells $/ \mathrm{mm}^{3}$ at initiation of ART. At this stage, the patient is in a state of advanced immune suppression (AIDS) exposed to serious opportunistic infections, moreover, we often see the appearance of several opportunistic infections and this state would lead to death.

The results also showed that comatose were 5 times more likely to die during the stay than non-comatose. The coma denotes a serious encephalic attack we attend an impossibility for the patient to eat. In the absence of adequate resuscitation, we witness the installation of a vicious circle. Lack of adequate nutrition in a previously undernourished patient further weakens the immune system, making this group of patients more likely to die.

Despite the interesting results of this study, it has limitations. Its retrospective nature did not make it possible to know the future of the referred patients, it also did not make it possible to find certain information notably the demonstration of the nonobservance to the TAR, the delay in the diagnosis and the recourse to the triple therapy of the patients.

\section{Conclusion}

This study showed that cerebral toxoplasmosis is associated with very high morbidity and mortality in the Infectious Diseases Department of Donka National Hospital. Living in a relationship, CD4 counts at baseline $<200 \mathrm{cells} / \mathrm{mm}^{3}$ and coma were independently associated with death. Special attention to these factors associated with infectious resuscitation and primary prevention in patients with a CD4 T lymphocyte count below 200 cells/mm may improve the prognosis of this pathology.

\section{Conflicts of Interest}

The authors declare no conflicts of interest regarding the publication of this paper.

\section{References}

[1] Opsteegh, M.A., Kortbeek, T.M., Havelaar, A.H. and Van-Der-Giessen, J.W.B. (2015) Intervention Strategies to Reduce Human Toxoplasma gondii Disease Burden. Clinical Infectious Diseases, 60, 101-107. https://doi.org/10.1093/cid/ciu721

[2] Luft, B.J. and Remington, J.S. (1992) Toxoplasmic Encephalitis in AIDS. Clinical Infectious Diseases, 15, 211-222. https://doi.org/10.1093/clinids/15.2.211

[3] Hill, D. and Dubey, J.P. (2002) Toxoplasma gondii: Transmission, Diagnosis, and Prevention. Clinical Microbiology and Infection, European Society of Clinical Infectious Diseases, 8, 634-640. https://doi.org/10.1046/j.1469-0691.2002.00485.x

[4] Andrei, V., Carmen, M. and Cristina, N. (2013) Clinical and Prognostic Features of Cerebral Toxoplasmosis in HIV Infected Patients-A Case Series Vâță et al. BMC Infectious Diseases, 13, P10.

https://bmcinfectdis.biomedcentral.com/articles/10.1186/1471-2334-13-S1-P10 https://doi.org/10.1186/1471-2334-13-S1-P10 
[5] De Gans, J. and Portegies, P. (1989) Neurological Complications of Infection with Human Immunodeficiency Virus Type 1. A Review of Literature and 241 Cases. Clinical Neurology and Neurosurgery, 91, 199-219. https://doi.org/10.1016/0303-8467(89)90114-5

[6] Ouedraogo, S.M., Ouedraogo, M., Dagnan, N.S., et al. (2007) Infections opportunistes au cours du Sida au CHU de Treichville. Mali Médical, 22, 26-28.

[7] Taoufik, L., Malika, I. and Fatima, I. (2016) La toxoplasmose cérébrale chez les patients infectés par le Virus de l'Immunodéficience Humaine au Maroc. Revue Francophone des Laboratoires, 2016, 78-82. https://doi.org/10.1016/S1773-035X(16)30376-8

[8] Henry, N.L., Benjamin, C.N.T. and Yacouba, N.M. (2013) Toxoplasma Encephalitis in HIV/AIDS Patients Admitted to the Douala General Hospital between 2004 and 2009: A Cross Sectional Study. BMC Research Notes, 6, Article No. 146.

https://bmcresnotes.biomedcentral.com/articles/10.1186/1756-0500-6-146 https://doi.org/10.1186/1756-0500-6-146

[9] Peltzer, K., Preez, N.F., Ramlagan, S. and Fomundam, H. (2008) Use of Traditional Complementary and Alternative Medicine for HIV Patients in KwaZulu-Natal, South Africa. BMC Public Health, 8, 255. https://doi.org/10.1186/1471-2458-8-255

[10] Nlooto, M. (2017) Comorbidities of HIV Infection and Health Care Seeking Behavior among HIV Infected Patients Attending Public Sector Healthcare Facilities in KwaZulu-Natal: A Cross Sectional Study. PLoS ONE, 12, e0170983. https://doi.org/10.1371/journal.pone.0170983

[11] Heestermans, T., Browne, J.L., Aitken, S.C., et al. (2016) Determinants of Adherence to Antiretroviral Therapy among HIV-Positive Adults in Sub-Saharan Africa: A Systematic Review. BMJ Global Health, 1, e000125. https://doi.org/10.1136/bmjgh-2016-000125

[12] Ketema, A.K. and Shewangizaw Weret, Z. (2015) Assessment of Adherence to Highly Active Antiretroviral Therapy and Associated Factors among People Living with HIV at Debrebrihan Referral Hospital and Health Center, Northeast Ethiopia: A Cross-Sectional Study. HIV AIDS, 7, 75-81. https://doi.org/10.2147/HIV.S79328

[13] Endale Gurmu, A., Teni, F.S. and Tadesse, W.T. (2017) Pattern of Traditional Medicine Utilization among HIV/AIDS Patients on Antiretroviral Therapy at a University Hospital in Northwestern Ethiopia: A Cross-Sectional Study. Evidence-Based Complementary and Alternative Medicine, 2017, Article ID: 1724581. https://doi.org/10.1155/2017/1724581

[14] Haile, K.T., Ayele, A.A., Mekuria, A.B., et al. (2017) Traditional Herbal Medicine Use among People Living with HIV/AIDS in Gondar, Ethiopia: Do Their Health Care Providers Know? Complementary Therapies in Medicine, 35, 14-19. https://doi.org/10.1016/j.ctim.2017.08.019

[15] Cissoko, Y., Seydi, M., Fortes, D.L., et al. (2013) Profil actuel de la toxoplasmose cérébrale en milieu hospitalier à Dakar. Médecine et Santé Tropicales, 23, 197-201. https://doi.org/10.1684/mst.2013.0179 